\title{
УДК 81’23
}

DOI: $10.18384 / 2310-712 X-2021-2-44-52$

\section{ОПЫТ ОПИСАНИЯ СЕМАНТИКО-СТРУКТУРНЫХ ОТНОШЕНИЙ МЕЖДУ ТЕРМИНАМИ (НА МАТЕРИАЛЕ АНГЛИЙСКОЙ ТЕРМИНОЛОГИИ ЛЕКСИКОЛОГИИ)}

\author{
Гринев-Гриневич С. В., Сорокина Э. А. ${ }^{2}$, Чернышова Л. А. ${ }^{3}$ \\ ${ }^{1}$ Государственная высшая профессиональная школа в Сувалках \\ 16-400, г. Сувалки, ул. Теофила Ноневича, д. 10, Республика Польша \\ 2 Московский государственный областной университет \\ 141014, Московская обл., г. Мытищи, ул. Веры Волошиной, д. 24, Российская Федерация \\ ${ }^{3}$ Российский университет транспорта (МИИТ) \\ 127994, г. Москва, ул. Образцова, д. 9, стр. 9, Российская Федерация
}

\section{Аннотация}

Цель. Представить лингвистическую терминологию как систему, в которой термины связаны гиперо-гипонимическими отношениями.

Процедура и методы. Представлен анализ семантико-структурных отношений между терминами, составляющими английскую лингвистическую терминологию в области лексикологии. Для исследования выбран терминологический материал, присутствующий в научной литературе и в учебниках, связанных с изучением лексики английского языка. Исследование проводилось с помощью статистического, десиниционного, структурно-семантического, компонентного методов.

Результаты. Проведённый анализ позволяет впервые представить понятийную структуру английской лексикологии как лингвистической дисциплины.

Теоретическая значимость исследования связана с возможным использованием его результатов в терминографии, терминоведении и в лингводидактике. Практическая значимость может быть определена возможным использованием языкового материала и результатов исследования в практике преподавания английской лексикологии, а также английского языка как иностранного.

Ключевые слова: термин, терминология, лексикология, лингводидактика, гипоним, гиперогипонимические отношения, родовидовые отношения

\section{A STUDY OF SEMANTIC RELATIONS BETWEEN TERMS (BASED ON THE ENGLISH TERMINOLOGY OF LEXICOLOGY)}

\author{
S. Grinev-Griniewicz ${ }^{1}$, E. Sorokina ${ }^{2}$, L. Chernyshova ${ }^{3}$ \\ ${ }^{1}$ State higher professional school in Suvalki \\ 10 ulitsa Teofila Noniewicza, Suwalki 16-400, Poland \\ ${ }^{2}$ Moscow Region State University \\ 24 ulitsa Very Voloshinoi, Mytishchi 141014, Moscow Region, Russian Federation \\ ${ }^{3}$ Russian University of Transport \\ 9 build. 9 ulitsa Obraztsova, Moscow 127994, Russian Federation
}

(с СС ВҮ Гринев-Гриневич С. В., Сорокина Э. А., Чернышова Л. А., 2021. 


\section{Abstract}

Aim. To present linguistic terminology as a system in which terms are linked by hyper-hyponymic and synonymic relations.

Methodology. The article presents an analysis of the semantic relations between terms that make up the English linguistic terminology in the field of lexicology. For the study, we selected terminological material that is present in the reference literature and manuals of the English language. To conduct the study, we used methods of statistical, definitional, structural and semantic and componential analysis.

Results. The analysis allows us to present for the first time the conceptual structure of English lexicology as a linguistic discipline.

Research implications. The theoretical significance of the study is associated with the possible use of its results in terminography, terminology and linguodidactics. The practical value can be determined by the possible use of the language material and the results of the study in teaching English lexicology and English as a foreign language.

Keywords: term, terminology, lexicology, linguodidactics, hyponym, hyper-hyponymic relations, generic relations

\section{Введение}

Поступательное развитие межгосударственных отношений привело к тому, что английский язык стал основным языком межкультурной коммуникации. При обучении английскому языку и при изучении его структуры основное внимание уделяется лексике, придавая этим лексикологии как одному из разделов англистики особое значение, что и определяет актуальность тех исследований, которые касаются проблемных вопросов англоязычной лексикологии. Описание результатов анализа лексикологии так же, как и обучение английскому языку, происходит при помощи особого исследовательского аппарата - лингвистической терминологии.

Лингвистическая терминология - это одна из разновидностей отраслевой терминологии, и ей свойственны многие признаки, выделяемые исследователями при анализе профессиональных языков, принадлежащих той или иной отрасли научного или научно-практического знания. Но обзор терминоведческих работ позволяет нам утверждать, что в настоящее время имеется незначительное количество трудов, посвящённых исследованию английской терминологии лексикологии, и при этом необходимо подчеркнуть, что английская лексикологическая терминология чаще всего анализировалась с позиции сопоставительного метода в сравнении с русской лингвистической терминологией. Считаем, что наше описание особенностей английской терминологии лексикологии, начатое с описания формы английских лексикологических терминов (см.: [2, с. 74]), даётся впервые.

\section{Проблема выделения лексикологической терминологии}

Изучение лингвистической терминологии осложняется тем, что лингвистические термины одновременно являются и предметом анализа, и средством описания процедур анализа (метаязыковая функция). Общая совокупность лингвистических терминов представляет собой слова и сочетания слов, при помощи которых возможен анализ и последующее описание составных структурных компонентов языка: фонетические термины, лексикологические термины, синтаксические термины, морфологические термины и т.д. Выделение лексикологической терминологии, т. е. тех слов и сочетаний слов, которыми обозначены явления, принадлежащие такому разделу языкознания, как лексика, в английском 
языке связано с решением нескольких проблемных вопросов.

Прежде всего возникает вопрос о сборе языкового материала для проведения анализа: какие работы могут служить источником? В нашем исследовании мы опирались на традиционные английские словари и ставшие уже тоже традиционными учебники по английской лексикологии.

Для сбора языкового материала были использованы следующие словари:

- «Оксфордский компаньон к английскому языку» (The Oxford companion to the English language, 1992) под редакцией Т. Мак-Артура (Т. McArthur). В названном словаре присутствуют 227 терминов, номинирующих понятия английской лексикологии [8];

- «Словарь лингвистики и фонетики» (A dictionary of linguistics and phonetics, 1997) ${ }^{1}$ Дэвида Кристала (D. Crystal), в котором наличествуют 124 термина, своим значением связанные с английской лексикологией;

- словарь Р. Л. Траска (R. L. Trask) «Словарь студента по языку и лингвистике» (A student's dictionary of language and linguistics, 1997) $)^{2}$, из которого было извлечено 127 лексикологических терминов;

- «Основные понятия языка и лингвистики» (Key concepts in language and linguistics, 1999) ${ }^{3}$, данный источник содержит 67 терминов по лексикологии;

- словарь Х.Джексона (Н. Jackson) «Основные лингвистические термины» (Key terms in linguistics, 2007) ${ }^{4}$, в этом источнике обнаружено 39 лексикологических терминов.

Методом сплошной выборки были отобраны лексикологические термины из энциклопедий: «Кембриджская энци-

\footnotetext{
Crystal D. A dictionary of linguistics and phonetics. $4^{\text {th }}$ ed. Oxford: Blackwell, 1997. XVI +426 p.

2 Trask R. L. A student's dictionary of language and linguistics. London: Arnold, 1997. 247 p.

3 Trask R. L. Key concepts in language and linguistics. London, New York: Routledge, 1999. 378 p. (Key Concepts Series).

4 Jackson H. Key terms in linguistics. London: Continuum, 2007. $192 \mathrm{p}$.
}

клопедия английского языка» (The Cambridge encyclopedia of the English language, $1995)^{5}$ известного английского лингвиста Дэвида Кристала (D. Crystal). Данная энциклопедия пополнила список лексикологических терминов 128 лексическими единицами; «Энциклопедия языка и лингвистики» (Encyclopedia of language and linguistics, 2005, 2-е, дополненное издание в 14 томах $)^{6}$ под редакцией английского лингвиста К. Брауна (К. Brown).

Языковой материал, необходимый для нашего исследования, был отобран и из учебников:

- Р. С. Гинзбург, С. С. Хидекель, Г. И. Князева, А. А. Санкин «Курс современной английской лексикологии» ${ }^{7}$;

- учебник немецкого автора Леонгарда Липки (Leonhard Lipka) «Общие черты английской лексикологии: лексическая структура, лексическая семантика и словообразование» (An Outline of English Lexicology: lexical structure, word semantics, and word formation, 1992) [6];

- раздел лексикологии учебника по введению в лингвистику С. В. Гринева и Э. М. Дубенец (Introduction to linguistics, 2001);

- учебник Э. М. Дубенец «Современная английская лексикология: теория и практика» (Modern English lexicology. Theory and practice, 2002);

- учебное пособие Э. М. Дубенец «Современный английский язык. Лексикология (Modern English: Lexicology, 2010) ${ }^{10}$;

\footnotetext{
5 Crystal D. The Cambridge encyclopedia of the English language. Cambridge, Cambridge University Press, 1995. VII +489 p.

6 Encyclopedia of language and linguistics. $2^{\text {nd }}$ edition. Volumes 1-14 / th ed. K. Brown Boston, Elsevier Science, 2005.

7 Курс современной английской лексикологии / Р. C. Гинзбург, С. С. Хидекель, Г. И. Князева, А. А. Санкин 2-е изд., испр. и доп. М.: Высшая школа, 1979. 269 с.;

8 Griniewicz S. W., Dubieniec E. M. Introduction to lin guistics. Białystok: Wydawnictwo WSFiZ, 2001. 79 S.

9 Дубенец Э. M. Modern English lexicology: Theory and Practice. М.: Глосса-Пресс, 2002. 196 с.

10 Дубенец Э. М. Современный английский язык. Лексикология / Modern English: Lexicology. M.: Глосса-Пресс, Феникс, 2010. 192 с.
} 
- а также единственный английский учебник Х. Джексона и Э. Зе Амвелы (H. Jackson, Е. Zй Amvela) «Слова, значение и лексика: Введение в современную английскую лексикологию (Words, Meaning and Vocabulary An introduction to modern English lexicology, 2007) [5].

Как уже нами отмечалось (см. [2, c. 77]), многие зарубежные работы по описанию английского языка базируются на традиционном американском подходе к системе языка, согласно которому ещё со времени Леонарда Блумфильда основной единицей признана морфема, а лексический уровень игнорируется.

Считаем, что подобное понимание структуры языка явилось причиной практически полного отсутствия в англоязычных странах учебников, посвящённых описанию такого весьма интересного и очень важного раздела английского языкознания, как лексикология. Может показаться странным, но в неанглоязычных странах учебники по английской лексикологии имеются.

Методом сплошной выборки мы собрали языковой материал в количестве 822 английских терминов, называющих явления, наблюдаемые в области лексики, и используемых в учебниках по английской лексикологии.

\section{Проблема выделения родовидовых отношений терминов}

Одним из сравнительно новых семантических отношений в лексике являются отношения гиперо-гипонимии (или просто - гипонимии), ранее известные в логике и научно-технической информации как родовидовые, а также иерархические отношения.

В лингвистике гипонимия - это явление, при котором одно понятие выражает частную сущность по отношению к другому, более общему понятию. Лексически гипоним - это слово, обозначающее частный вид понятия, обозначенного гиперонимом.

Проведённый нами обзор современной лингвистической литературы позво- ляет говорить о том, что, к сожалению, явление гипонимии в настоящее время почти не привлекает внимания лингвистов. В обзорной части статьи арабских авторов Муайада Мингера АлШеммури и Имана М. АлШеммури «Усвоение гипонимии университетскими студентами иностранных языков», датированной 2017 г., в большинстве публикаций гипонимия как явление упоминается мимоходом и при этом, заметим, что большинство подобных работ относится к XX в. [4, p. 3-17].

В отечественном языкознании явление гипонимии рассматривалось в 1970 80 гг. в связи с созданием нескольких сотен информационно-поисковых словарей-тезаурусов, основанных на иерархическом принципе, а затем только упоминалось в учебниках и справочниках.

В данной статье мы не ставим перед собой целью обстоятельный анализ самого явления гипонимии и особенностей его функционирования, а только констатируем наличие гипонимических отношений при системном описании терминологии лексикологии.

Следует заметить, что в настоящее время в иерархических отношениях различаются два вида гипонимии - таксономическая и функциональная - по терминологии М. Мэрфи [7, р. 185-189]. Первая из них (таксономическая) является обязательной, тогда как вторая (функциональная) реализуется лишь в некоторых ситуациях. Так, имя существительное всегда является частью речи, а в некоторых ситуациях может быть сказуемым. В научно-технической информации к иерархическим отношениям причисляется и меронимия (партонимия).

Исследования показали, что анализ отношений гипонимии оказался чрезвычайно полезным для установления особенностей структуры терминологий, выявления системности термина, выделения лексических групп и семантических полей.

В английской терминологии лексикологии, где нами впервые были установле- 
ны гипонимические отношения, термины распределяются по трём категориям - объекты (включая явления), процессы и свойства. При этом наполнение этих категорий терминами оказывается неравным: наиболее полно представлены объекты - 442 понятия, выраженные 672 терминами, менее детально представлена категория процессов - 73 понятия (121 термин), и наименьшей оказалась категория свойств - 25 понятий (29 терминов).

Вполне очевидно, что наполнение категории терминами отражает степень её изученности. Считаем, что наиболее изученной является категория объектов, поскольку в ней глубина иерархии может насчитывать до 7 уровней, например:

<lexicological objects (лексикологические объекть) $>$

.. lexemes (лексемь)

... proper namеs (имена собственные)

.... anthroponyms (names) (личные имена) звиниe)

..... nickname (by-name, byname) (npo-

...... pet name (ласкательное имя)

....... diminutive (уменьшительно-ласкательное имя)

Гипонимические отношения между этими терминами диктуют определённое место каждому понятию.

К категории объектов относятся следующие группы понятий: лексемы, форманты, значения, группы слов, области знания, лексические явления.

Группа областей знания, большинство из терминов которой (39 терминов) - это названия разделов лексикологии, содержит 29 понятий, выраженных 47 терминами. Данная группа уже может дать представление о сложной структуре понятия «лексикология»: в число её основных разделов входят historical lexicology, onomasiology, semasiology, onomastics, phraseology, comparative lexicology, contrastive lexicology, descriptive lexicology (историческая лексикология, ономасиология, семасиология, ономастика, фразеология, сопоставительная, контрастивная и описательная лексикология).
Примыкают к лексикологии и непосредственно связаны с нею terminology science, lexicography, dialectology, stylistics (терминоведение, лексикограбия, диалектология, стилистика).

Отметим, что каждый из обозначенных терминов может быть элементом первого (начального) уровня и иметь в своей иерархии разное количество гипонимически связанных компонентов.

Наиболее обширной является группа лексем (lexemes), включающая 283 понятия, обозначенные 453 терминами.

Заметим, что в современной языковедческой науке существуют различные подходы к определению понятия лексема. Мы понимаем под лексемой слово или устойчивое словосочетание (фразеологизм), эквивалентное слову (ср.: [3, с. 96; 8, р. 600]).

В соответствии с аспектами изучения лексем (структура лексем, значение лексем, функционирование лексем, образование лексем и исторический статус), будучи элементом первого уровня, термин «лексема» (lexeme) имеет гипонимически связанные с ним элементы:

- structural types of lexemes - структурные типы лексем (с делением на слова и словосочетания - words and word-combinations);

- derivational types of lexemes - деривационные типы лексем;

- chronological types of lexemes - xpoнологические типы лексем;

- semantic types of lexemes - семантические виды лексем;

- functional types of lexemes - функциональные типы лексем.

Подгруппа «Structural types of lexemes - Структурные типы лексем» достаточно велика - 28 понятий (69 терминов) - и отражает современную структурную типологию терминов, в которой в первую очередь выделяются слово (word) и словосочетание (word-combination).

Далее слова структурно делятся на три подтипа: простое (корневое) слово (simple word), аффиксальное слово (complex word) и сложное слово (compound 
word). Разница между терминами complex word и compound word почти неощутима, и на русский язык они переводятся одинаково - сложное слово, поэтому в своих публикациях на английском языке мы используем вместо термина complex word мотивированный термин с прозрачной семантикой affixal word.

Близка к этой подгруппе обширная подгруппа «Лексемы по способу образования», которая насчитывает 175 терминов, называющих 123 понятия. Эта подгруппа содержит наименования разновидностей дериватов, образованных аффиксацией, словосложением, аббревиацией и заимствованием.

Иногда понятия структурного типа лексемы и способа её образования путают, поскольку affixal word (афбфиксальное слово) можно понимать и как слово, имеющее аффиксы (структура) и, как слово, образованное аффиксацией, a compound word (сложное слово) как слово, имеющее в своём составе два и более корня, и как слово, образованное осново- или словосложением.

Тем не менее разница между этими понятиями существенна: слова с суффиксами или сложные слова могут быть образованы заимствованием, конверсией, эллипсисом, а один способ образования (например, заимствование или семантический сдвиг) даёт слова с разной структурой. Сюда могут относиться непроизводные слова и различные виды производных и сложных слов (phrase из древнегреческого, argot, barbarism и derivative - из французского, loanword - из немецкого языков).

К небольшой подгруппе «Хронологические типы лексем» (23 понятия, обозначенные 32 терминами) относятся наименования разновидностей устаревщих слов и неологизмов.

Весьма обширной является подгруппа терминов, именующих семантические виды лексем (79 понятий и 127 терминов, эти понятия называющих), что отражает разработанность соответствующей области знаний.
Данная группа включает наименования видов синонимов (25 понятий - 33 термина), видов антонимов (7 понятий - 15 терминов), типов омонимов (6 понятий - 10 терминов), паронимов (4 понятия - 5 терминов), многозначных лексем (1 понятие - 3 термина), гипонимов и гиперонимов (3 понятия - 8 терминов), appellatives нарицательных имён (1 понятие - 4 термина), имён собственных (28 понятий - 45 терминов).

К подгруппе функциональных видов лексем относятся вульгаризмы, жаргонизмы, регионализмы, окказионализмы и специальные лексемы - термины и профессионализмы, всего 30 понятий, обозначенных 50 терминами.

С вопросами структуры и образования лексем связаны понятия формантов. В группе «Форманты», насчитывающей 52 понятия, называемых 62 терминами, относятся наименования разновидностей основ и лексических морфем (корней и аффиксов).

Сравнительно небольшой является группа видов лексических значений - 10 понятий и 27 терминов.

Группа наименований различных лексических классов (лексические группы, словарный запас, сленг, терминология) включает 21 понятие и относящиеся к данным понятиям 26 терминов.

К категории объектов относится и группа «лексические явления» (в основном семантические), включающая 37 понятий, поименованных 51 термином.

Для категории процессов, к которой относятся 73 понятия и соответствующий им 121 термин, глубина иерархии составляет 6 уровней:

Lexicological processes (лексические процессы)
. nomination
(номинация)
.. word building
(словообразование)
... conversion (конверсия)
.... substantivation (субстантивация)
..... perfect substantivation (полная субстантивация)
......partial substantivation (частич- ная субстантивация). 
Большинство понятий и терминов этой категории (62 понятия и 101 термин) относятся к различным видам номинации - заимствованию, семантическим сдвигам, деривации, аббревиации и др.

В категории свойств, к которой относится 25 понятий и 29 терминов, глубина иерархии достигает только четвёртого уровня, что даёт основание предполагать, что эта категория менее исследована:

Lexicological properties (свойства)

- motivation (мотивация, мотивированность)

.. structural motivation (morphological motivation)

... phonetic motivation (phonetical motivation)

.... semantic motivation

Проведённый анализ английской лексикологической терминологии и собранные нами статистические данные позволяют говорить о том, что многие лексикологические понятия имеют несколько наименований, следовательно, в лексикологической терминологии широко представлены со-гипонимия и синонимия терминов.

\section{Выводы}

Исследование, осуществлённое на материале английской лингвистической терминологии, позволило впервые описать и представить характер английской терминологии лексикологии.
При этом практика установления гипонимических отношений показывает эффективность их первоочередного рассмотрения. Во-первых, это позволяет выявить структуру изучаемой терминологии, а, во-вторых, позволяет одновременно выявить многозначность и синонимию, поскольку одинаковая лексическая форма с разным значением окажется в разных местах гипонимической системы, а полные синонимы будут соотнесены с одним понятием.

Рассмотрение семантических особенностей терминологии, начиная с выявления гипонимических отношений составляющихеётерминов, соответствует традиционной стандартной очерёдности терминологических операций (см.: [1, c. 19]).

Практическое применение анализа гипонимических отношений в преподавании иностранной лексики, особенно специальной, позволяет обучаемым составить системное представление об изучаемой области знаний и значительно повышает эффективность обучения.

Терминоведческий анализ семантических явлений должен восприниматься обязательным элементом упорядочения терминологий и может быть использован в определении состояния и прогнозирования развития различных областей знания.

Статья поступила в редакцию 11.01.2021

\section{ЛИТЕРАТУРА}

1. Гринев-Гриневич С. В. Терминоведение: учеб. пособие для студ. высш. учеб. заведений. М.: Издательский центр «Академия», 2008. 304 с.

2. Гринев-Гриневич С. В., Сорокина Э. А. Опыт описания формальной структуры термина (на материале английской терминологии лексикологии) // Вестник Московского государственного областного университета. Серия Лингвистика. 2020. № 5. С. 74-90. DOI: 10.18384/2310-712X2020-5-74-85.

3. Маслов Ю. С. Введение в языкознание. М: Высшая школа, 1987. 272 с.

4. Al-Shemmery M. M., Obied I. M. The Acquisition of Hyponymy by Iraqi EFL University Students // Basic Education College Magazine for Educational and Humanities Sciences. 2017. Iss. 34. P. 403-414.

5. Jackson H., Zé Amvela E. Words, Meaning and Vocabulary An introduction to modern English lexicology; 2nd ed. New York: Continuum, 2007. 260 p.

6. Lipka L. An Outline of English Lexicology: lexical structure, word semantics, and word formation; 2. ed. Tübingen: Niemeyer, 1992. $218 \mathrm{p}$. 
7. Murphy Lynne M. Semantic relations and the lexicon: antonymy, synonymy and other paradigms. Cambridge: Cambridge University Press, 2003. 304 p.

8. The Oxford companion to the English language (OCEL) / ed. T. McArthur. Oxford, New York: Oxford University Press, $1992.651 \mathrm{p}$.

\section{REFERENCES}

1. Grinev-Grinevich S. V. Terminovedenie [Terminology]. Moscow, Akademiya Publ., 2008. 304 p.

2. Grinev-Grinevich S. V., Sorokina E. A. [Describing the formal structure of a term (based on the English terminology of lexicology)]. In: Vestnik Moskovskogo gosudarstvennogo oblastnogo universiteta. Seriya Lingvistika [Bulletin of the Moscow Region State University. Series: Linguistics], 2020, no. 5, pp. 74-90. DOI: 10.18384/2310-712X-2020-5-74-85.

3. Maslov Yu. S. Vvedenie v yazykoznanie [Introduction to linguistics]. Moscow, Vysshaya shkola Publ., 1987. $272 \mathrm{p}$.

4. Al-Shemmery M. M., Obied I. M. The Acquisition of Hyponymy by Iraqi EFL University Students. In: Basic Education College Magazine for Educational and Humanities Sciences, 2017, iss. 34, pp. 403-414.

5. Jackson H., Zé Amvela E. Words, Meaning and Vocabulary An introduction to modern English lexicology; 2nd ed. New York, Continuum Publ., 2007. 260 p.

6. Lipka L. An Outline of English Lexicology: lexical structure, word semantics, and word formation; 2. ed. Tübingen, Niemeyer Publ., 1992. 218 p.

7. Murphy Lynne M. Semantic relations and the lexicon: antonymy, synonymy and other paradigms. Cambridge, Cambridge University Press Publ., 2003. 304 p.

8. McArthur T., ed. The Oxford companion to the English language (OCEL). Oxford, New York, Oxford University Press Publ., 1992. 651 p.

\section{ИНФОРМАЦИЯ ОБ АВТОРАХ}

Гринев-Гриневич Сергей Викторович - доктор филологических наук, профессор, доктор гуманитарных наук, звычайный профессор Государственной высшей профессиональной школы в Сувалках;

e-mail: svgrinev1@gmail.com.

Сорокина Эльвира Анатольевна - доктор филологических наук, профессор, профессор кафедры английской филологии Московского государственного областного университета;

e-mail: ellasor@mail.ru;

Чернышова Лариса Анатольевна - доктор филологических наук, заведующий кафедрой «Лингвистика» Института экономики и финансов Российского университета транспорта (МИИТ)

e-mail: chernyshovalor@gmail.com

\section{INFORMATION ABOUT THE AUTHORS}

Siergiej V. Grinev-Griniewicz - Dr. Sci. (Philology), Dr. Sci.(Humanities), Prof., State higher professional school in Suvalki;

e-mail: svgrinev1@gmail.com;

Elvira A. Sorokina - Dr. Sci. (Philology), Prof., Department of English Philology, Moscow Region State University;

e-mail: ellasor@mail.ru;

Larisa A. Chernyshova - Dr. Sci. (Philology), Departmental Head, Department of Linguistics, Institute of Economics and Finance, Russian University of Transport (MIIT);

e-mail: chernyshovalor@gmail.com 


\section{ПРАВИЛЬНАЯ ССЫЛКА НА СТАТЬЮ}

Гринев-Гриневич С. В., Сорокина Э. А., Чернышова Л. А. Опыт описания семантико-структурных отношений между терминами (на материале английской терминологии лексикологии) // Вестник Московского государственного областного университета. Серия: Лингвистика. 2021. № 2. С. 44-52. DOI: $10.18384 / 2310-712 \mathrm{X}-2021-2-44-52$

\section{FOR CITATION}

Grinev-Griniewicz S. V., Sorokina E. A., Chernyshova L. A. A study of semantic relations between terms (based on the English terminology of lexicology). In: Bulletin of the Moscow Region State University. Series: Linguistics, 2021, no. 2, pp. 44-52.

DOI: 10.18384/2310-712X-2021-2-44-52 